\title{
Excess Heat-Related Mortality in Micro-Urban Heat Islands: A Case-only Study in Barcelona
}

\author{
John-Paul GLUTTING \\ AIR Worldwide, Boston/USA · jpglutting@gmail.com \\ This contribution was double-blind reviewed as full paper.
}

\begin{abstract}
Background: Extreme heat events (EHE) are of increasing public health concern. In urban areas, micro-urban heat islands (MUHI) raise the possibility of increased mortality risk. This study identified MUHI in the city of Barcelona, Spain, using Landsat 7 thermal infrared imagery and overlaid them onto at-home deaths between 2000-2003, identified from a mortality registry and geocoded using the Google API. Hot days were defined as days with mean minimum temperatures above the $90^{\text {th }}$ percentile of historic temperatures. Data were analyzed using a case-only design, with a logistic regression model adjusted for spatial autocorrelation. Results: In the period 2000-2003, at-home deaths in MUHI were associated with $15 \%$ greater odds of dying on hot days than at-home deaths outside of MUHI. Conclusions: MUHI were a risk factor for at-home deaths during EHE in the study period (2000-2003) in the city of Barcelona. In urban areas facing similar conditions (limited use of air-conditioning, among others), residents of MUHI may be at increased mortality risk during extreme heat events.
\end{abstract}

\section{Introduction}

Extreme heat events (EHE), some of which are commonly known as "heat waves", have been an issue of increasing concern and research in recent years, especially after the high mortality experienced during a series of European EHE between 2003 and 2006 (FouILLET et al. 2008, KOVATS \& HAJAT 2008). Recently published climate models project increases in the frequency, duration and intensity of EHE in the latter half of this century (GosLING et al. 2008). MEEHL \& TEBALDI (2004) have noted that these changes are expected to affect the Mediterranean area disproportionately.

Heat effects are particularly detrimental to certain sub-populations: the elderly (INIIGUEZ et al. 2010; O'NeILL et al. 2009), the poor (O'NEILL et al. 2009; BASU 2009), minorities (BASU 2009; SCHWARTZ 2005), the mentally ill (HANSEN et al. 2008), outdoor workers (KINNEY et al. 2008), the bedridden (BOUCHAMA et al. 2007) and people who take certain types of medications that interfere with electrolytes and water balance (e.g., diuretics, anticholergic agents, and tranquilizers that impair sweating) (LUBER \& MCGEEHIN 2008, HANSEN et al. 2008; JOHNSON et al. 2009; MARTINN-LATRY et al. 2007). Heat may kill so quickly that hospital admissions do not reflect the full scale of mortality (KOVATS \& HAJAT 2008); some authors report that most victims are found dead in their residences (BOUCHAMA et al. 2007). 
The goal of this project was to identify spatial risk factors associated with increased mortality during EHE in the city of Barcelona, Spain. The methods used were the creation and testing of a place-based heat vulnerability map for the city of Barcelona using a caseonly study design. Four data sets (mortality, weather, infrared imaging and census data) were processed to produce the final dataset used in the analysis. One spatial factor out of many that affect exposure to heat is the urban heat island (UHI) effect, which causes cities to have higher temperatures than their less urbanized surroundings, due to hard surfaces that absorb heat (steel, cement, asphalt), building density, wind and the effect of the built environment on wind direction and speed, and lack of vegetation. Urban areas also show high variability in surface temperatures over short distances (NICHOL et al. 2009), variations commonly referred to as "micro-urban heat islands" (MUHI). MUHI have been associated with increased mortality risks in previous publications (JOHNSON et al. 2009; KESTENS et al. 2011; SMARGIASSI et al. 2009). MUHI are important because they affect densely populated areas, thus putting large numbers of people at risk.

\section{Input Data and Data Processing}

\subsection{Data Sets}

Four data sets were used: 1) Mortality data for 2000-2003, April-September (inclusive). As the source of these data was a mortality registry, only address (residential and address of death), age and sex were provided for each subject. Only at-home deaths during the warm season (April-September) were considered. 2) Meteorological data for 2000-2003, AprilSeptember (inclusive). Data from two weather stations were used, including mean, minimum and maximum daily temperatures, as well as relative humidity and air pressure. 3) Landsat 7 thermal infrared (TIR) images from the years 2000-2002 (nine images). These images have a 60 meter resolution, resampled to 30 meters, taken from Landsat 7 band 6: $10.4-12.5 \mu \mathrm{m} .4$ ) Census data for the year 2001 (to calculate population density). Population density was calculated from census tract size and tract population.

\subsection{Data Processing}

The final dataset consists of geocoded at-home mortality data linked with other types of data in a PostGIS database (version 2.0 SVN revision 7799). Street addresses where athome deaths took place were geocoded and mapped over layers containing meteorological information, TIR imagery, as well as census tracts and associated measures (population density). All data were transformed to the WGS84 datum and the UTM 31N geographical coordinate system (EPSG:32631). Additional analytical functions were performed using the $\mathrm{R}$ statistical package, gdalwarp and a modified version of MCElite (software previously developed by the author). Additional analysis used the $\mathrm{R}$ statistical package for regression analysis. 


\subsubsection{TIR Images}

Standardized scores for each pixel position in the study area were generated based on radiance values from the nine Landsat 7 TIR images that fulfilled the inclusion criteria ( $<10 \%$ clouds). Radiance byte values $(0-255)$ from each pixel were used to calculate mean and standard deviation (SD) values and finally z-score for each pixel, based on the previously calculated population parameters (mean and SD). The results were rasters of $\mathrm{Z}$-scores indicating the relative radiance (ZRR - to distinguish the acronym from the risk ratio) at each position in the study area. All the selected z-score rasters were averaged to produce a single raster with mean ZRR scores, to indicate the averaged ZRR for each pixel area. This final raster represented the ZRR of each location as compared to the rest of the study area, averaged over multiple images for reliability. The z-scores served as a proxy for relative differences in land surface temperatures (LST) across the study area at any given temperature or time. No analysis of land use or ground cover was conducted.

Figure 1 shows the averaged ZRR scores across the study area. There were relatively minor differences between images, as evidenced by the easily identifiable patterns of streets and buildings in the southern portion of the study area, even in the averaged image.

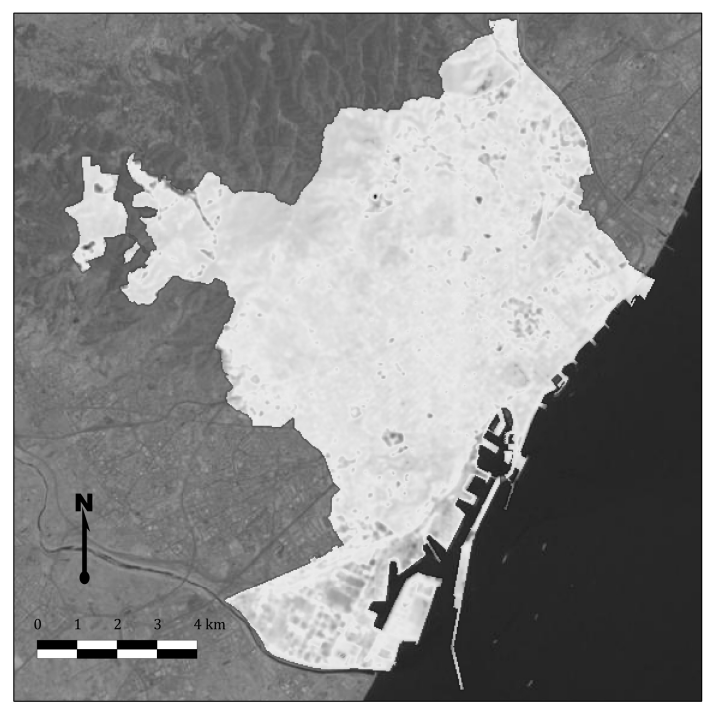

\section{Fig. 1:}

Pseudocolor representation of averaged radiance (z-score) from Landsat 7 thermal infrared images (Barcelona 2000-2002). The pseudocolor image reflects the averaged $\mathrm{z}$-scores from the nine raster images used in the study.

\subsubsection{Weather Data}

Temperature data was used from two stations that collected humidity data (used to calculate apparent temperature) and were operational during the study period (the Observatori Fabra and Barcelona weather stations). Only the Observatori Fabra station was operational for the entire study period. The Observatori Fabra station is located above most of the populated areas of Barcelona, partially up the Collserola mountain in a wooded area. The Barcelona station was located in the city itself, near the Arc de Triomf. Between the two, they cover a range of conditions in the city, as well as a vertical distance of 403.7 meters the Barcelona weather station is 7.5 meters above sea level and the Observatori Fabra station is located 411.2 meters above sea level. Temperatures were recorded as the mini- 
mum, maximum and mean for each day (there were no hourly measures) and were calculated for 0-3 days of lag (the mean of the index day and the index day with 1-3 previous days). Zero days of lag is included to compare the effect of the index day to lagged measures.

Missing values in the data set were imputed using a linear regression method based on the historic correlation between temperatures at the two weather stations using data from 1996 to 2008 .

\subsubsection{Geocoding Mortality Data}

Addresses were cleaned to remove "vertical" information (floor, apartment number, etc.) and formatted for the Google API (Version 3). Only geocoded addresses that met defined quality criteria were used in the study. Each address returned by the API had to be an exact match on the five address elements of the submitted address (street number, street name, postal code, city, country) and only addresses with the Google location type of "Rooftop" or "Range interpolated" were accepted. Of the 32,584 street addresses in the initial dataset, 26,681 met the defined geocoding quality criteria, representing a total of 50,637 deaths. Of these deaths, 12,124 had the same address for both residence and death - that is, they were deaths in the home. The study period (April to September) between 2000-2003 included 5,554 geocoded, at-home deaths.

\section{Statistical Analysis}

A case-only design was used, a methodology for studying risk factors that modify the effects of a given type of exposure. Case-only methods can be used to analyze a single, time-fixed modifier of a given time-variable exposure in a set of cases over time (SCHWARTZ 2005a; ARMSTRONG 2003; MEDINA-RAMÓN \& SCHWARTZ 2008). In this study, the exposure variable was high air temperature $(\mathrm{HAT}+/-)$ based on a percentile threshold of historical temperature data, and the modifier variable was high relative radiance (HRR+/-) based on the averaged z-scores from the raster data. HRR+ defined the MUHI. Cases were deaths registered in a mortality registry and the time units analyzed were days during the study period. Table 1 shows the $2 \times 2$ table for the calculation of the odds ratio.

Table 1: A 2x2 table for a case-only design. Exposure (High Air Temperature [HAT]) in the rows and the modifier (High Relative Radiance [HRR]) in the columns.

\begin{tabular}{|c|c|c|c|c|}
\hline & & \multicolumn{2}{|c|}{ Modifier } & Proportion \\
\hline & & HRR $=1$ & HRR $=0$ & \\
\hline \multirow{2}{*}{ Exposure } & $\mathrm{HAT}=1$ & $\mathrm{~A}$ & $\mathrm{~B}$ & $\mathrm{~A} /(\mathrm{A}+\mathrm{B})$ \\
\cline { 2 - 5 } & $\mathrm{HAT}=0$ & $\mathrm{C}$ & $\mathrm{D}$ & $\mathrm{C} /(\mathrm{C}+\mathrm{D})$ \\
\hline
\end{tabular}

The null hypothesis was $\mathrm{H} 0: \mathrm{AD} / \mathrm{CB}=1.0$. Under the alternative hypothesis, that HRR was a risk factor for death during EHE, the odds ratio (OR) would be greater than one. An 
OR less than one would indicate that HRR had a protective effect on deaths during EHE. The odds ratio can be modeled as a logistic regression (SCHWARTZ 2005b).

A different regression was done for each temperature type (apparent and normal) and measure (minimum, maximum, mean), with the HAT variable set to one for days in which the temperature measure was above the 90th percentile for that type and zero otherwise. HRR was defined as one only when the z-score registered for the location of death was greater than zero, and zero otherwise.

\subsection{Modelling Lag}

The R package for Distributed Lag Nonlinear Models (DLNM) was used to examine the effect of lagged mortality on overall mortality. Lagged temperatures were calculated as the averages of the current and 0-3 previous days' temperatures.

\subsection{Regression Formula}

Multiple models were fitted and compared using the corrected Akaike Information Criteria (AICc), as described in the Results section.

The generic regression formula used was as follows: HRR HAT_ttype_lag $+\delta+$ fitted(spatial_lag_model) where HRR is a dichotomous variable representing whether a death occurred in a high radiance (high z-score) area, HAT_ttype_lag represents the values for one combination of the two temperature types (apparent and normal) and the four lags (0-3 days) used in the analysis, with $H A T$ being a dichotomous variable representing whether the death took place on a day in which the air temperature measure of a certain type (ttype) was above the 90th percentile of historical temperatures at a certain lag (lag), $\delta$ is the array of explanatory variables or cofactors used (age, sex and population density), and spatial_lag_model was the model used to adjust for spatial autocorrelation.

\subsection{Spatial Autocorrelation}

The variables age and sex were significantly, although not strongly, spatially autocorrelated, with Moran's I values of 0.023 ( $\mathrm{p}$-value $=7.88 \mathrm{e}-50)$ and 0.01 ( $\mathrm{p}$-value=1.22e-10), respectively. After correction for spatial autocorrelation, the significance of the regression models was reduced slightly when compared to the unadjusted models (not shown). An adjustment for spatial autocorrelation was included in the final regression model. Adjustment was done using the Moran's Eigenvector GLM Filtering (ME) package in R (DRAY et al. 2006). This software uses brute force eigenvector selection to eliminate part of the spatial autocorrelation in a general linear model; in this case the regression model used a logistic (logit) link. The adjustment function was based on the regression formula with all the included cofactors, and the resulting model (a set of selected eigenvectors) was included in the final regression model as a cofactor. 


\section{$4 \quad$ Results}

Odds ratios, $\mathrm{p}$-values and corrected AICc values were calculated for multiple models of athome deaths during the study period, and are shown in Table 2. The models tested were compared using the AICc values, based on RelAIC, a method of calculating the relative probability that a given model minimizes information loss when compared to the best fitting model, $m_{\min }$.

The formula for calculating the RelAIC for model $i$ is:

$$
\exp \left(\left(A I C c_{\text {min }}-A I C c_{i}\right) / 2\right)
$$

A common rule of thumb for comparing AIC values is the AIC delta method (LOGAN 2010), in which models with deltas less than two in their AIC scores are considered equally valid. The equivalent RelAIC threshold is a value greater than 0.35 . Results with p-values below 0.10, which also have RelAIC scores $>0.35$ (and therefore AIC deltas below 2.0), are shown in Table 2. Model selection is not an exact science, but some inferences can be drawn from these results. All of the best fitting models show positive correlations and significant (or nearly significant) p-values. In addition, the lower the AICc scores, the more significant the results. These findings are entirely consistent with the data, as the different lags and temperature measures are largely overlapping, and a gradient of risk is a valid interpretation.

The best fitting models were centered around two days of lag, and minimum temperatures. This lag is consistent with the lag modeling done using the DLNM testing of the mortality data (not shown). Minimum temperatures represent a measure that has been highlighted in earlier research (BACCINI et al. 2011; BACCINI et al. 2008). The theoretical explanation for the impact of high minimum temperatures on health is that this temperature represents the level of physiological respite from heat that an organism gets at night. With high minimum temperatures, it is difficult to recover from daytime heat stress (in the absence of airconditioning), and therefore this measure represents an absolute threshold of stress on a population in a 24-hour period. Thus, the good performance of minimum temperature measures has a sound theoretical basis.

Table 2: Results of Logistic Regression

\begin{tabular}{|c|c|c|c|c|c|c|c|}
\hline \multicolumn{2}{|c|}{ Temperature } & Lag & $\begin{array}{c}\text { Odds } \\
\text { Ratio }\end{array}$ & $\mathbf{9 5 \%}$ CI & p-value & AICc & RelAIC \\
\hline Type & Measure & Days & & & & & \\
\hline Apparent & Minimum & 1 & 1.149 & $1.001-1.32$ & 0.048 & 6517.011 & 0.899 \\
\hline Normal & Minimum & 1 & 1.131 & $0.987-1.298$ & 0.076 & 6517.750 & 0.621 \\
\hline Apparent & Mean & 2 & 1.131 & $0.987-1.298$ & 0.076 & 6517.765 & 0.616 \\
\hline Normal & Mean & 2 & 1.131 & $0.987-1.298$ & 0.076 & 6517.765 & 0.616 \\
\hline Apparent & Minimum & 2 & 1.150 & $1.003-1.319$ & 0.046 & 6516.910 & 0.945 \\
\hline Normal & Minimum & 2 & 1.151 & $1.005-1.319$ & 0.043 & 6516.797 & 1.000 \\
\hline Apparent & Minimum & 3 & 1.143 & $0.996-1.312$ & 0.057 & 6517.295 & 0.780 \\
\hline Normal & Minimum & 3 & 1.137 & $0.992-1.302$ & 0.068 & 6517.488 & 0.708 \\
\hline
\end{tabular}


The choice between apparent and normal temperatures was one in which AICc scores are not clear indicators of a good model because the values are so similar. Apparent temperature has an underlying physiological explanation, which is that relative humidity is an important factor in physiological stress because it makes temperature regulation through sweating less effective (BASU 2009; METZGER et al. 2010). As such, it potentially models actual heat stress better than a simple measure of air temperature. This measure was also used by BACCINI et al. $(2011 ; 2008)$ in their study of heat effects in 15 European cities (including Barcelona). On the other hand, for practical purposes, humidity has been found to be a less useful measure for interventions such as developing heat health watch warning systems (HHWWS), as it is difficult to predict accurately (HAJAT et al. 2010).

The odds ratio for the best fitting model, using minimum normal temperatures averaged over two days of lag as predictors, was 1.151 (95\% CI: $1.005-1.319$; p-value $=0.043$ ), indicating a $15 \%$ increase in the odds of death in MUHI during EHE.

\section{Discussion and Conclusion}

Based on the results of the statistical analysis, micro-urban heat islands were a significant risk factor for mortality during the years 2000-2003 in Barcelona. At-home deaths in a MUHI were associated with $15 \%$ greater odds of dying on hot days than at-home deaths outside of MUHI.

There are important aspects of this method for examining the association between MUHI and mortality during EHE that could be expanded, for example, to better characterize the role of socio-economic status or air-conditioning (AC) usage on the relationship. Nevertheless, this method of examining the effect of MUHI on mortality during EHE could be useful if applied to other urban areas. It would probably be most effective in places where the use of AC is not yet widespread (either in developing countries or areas that have not historically experienced high warm-season temperatures).

\section{Study Decisions}

In-home deaths were used for several reasons. First, heat-related mortality tends to take place among the elderly and in the home (BOUCHAMA et al. 2007). Secondly, it is difficult to determine if persons dying outside the home or in hospitals were exposed to recent heat in their area of residence (they may have been hospitalized for a significant period of time or may have been staying at another address), whereas at-home deaths mean the deceased necessarily experienced local conditions at the time of death (with the exception of those found more than one day after death, but proper death certificates should include probable time of death). An additional issue is the cause of death. Because EHE can affect human physiology in multiple and not entirely understood ways (interactions with medications, food poisoning, etc.) (BouchAMA et al. 2007; O’NEILL et al. 2009), there are two principal types of causes of death typically used in studies of heat-related mortality: specific cause (cardiovascular or asthma, for example) or all-cause, excluding accidents. Currently, there is no systematic definition of heat-related mortality (BASU 2009), making overspecification of causes of death potentially counter-productive, resulting in missing some effects of EHE on mortality. Many researchers use all-cause mortality due to potential misclassification; sometimes very few deaths are classified as heat-related, and these definitions vary by 
location (BASU \& SAMET 2002). This study used all-cause mortality, including accidents, as there was no way to exclude them. However, at-home deaths excluded traffic accidents, one of the larger causes of accidental mortality.

\section{Appropriateness of a Case-Only Design for this Study}

The analytical method chosen was a good fit for the project, as it was well adapted to the data available (only cases, limited cofactors) and an estimate of the exposure effect in Barcelona is not needed, as this work has already been done (MATTHIES \& MENNE 2009; BACCINI et al. 2011; BACCINI et al. 2008; SAÉZ et al. 2000). Because the available, spatially located mortality data had only two cofactors (age and sex), modeling interactions would have been limited, even using a more complex analytical methodology. Also, the cancellation of cofactors in the case-only design tends to limit the effect of confounding variables.

\section{Confounding in case-only studies}

There are three specific types of confounding that can affect a case-only study. In decreasing order of importance, they are: interactions between the exposure and the modifier (in this study these were air temperature and relative surface radiance at specific points in the city); interaction between the modifier and another time-variable parameter (in this study relative surface radiance and some other time-variant variable that would confound air temperature such as flu epidemics, air pollution, etc.); and interaction between the exposure and one or more of the time-fixed variables (for example, air temperatures and one or more of: age, sex, chronic disease, socio-economic status, etc.).

In the first case, it seems true that the radiance of an urban area would interact with air temperatures locally, but the relative radiance was calculated as a differential from the mean values for the study area, and thus changing the mean air temperatures over the study area would not confound because of the scale differences - the daily mean temperatures were calculated as a constant across the whole study area (spatial dimension), while the HRR scores varied across the study area. As for the second type of confounding, it is known that ozone production increases with heat (SCHWARTZ 2005b), and ozone increases mortality, so this is a potential confounding factor in areas with higher LST, although Schwartz found no evidence of this in his research. With regard to the third type of confounding - interactions between the exposure variable and other time-fixed modifiers of interest - it seems unlikely that daily air temperatures across the study area could either modify or be modified by time-fixed variables such as population density, sex, age at death or other unidentified timefixed factors.

\section{References}

Armstrong, B. G. (2003), Fixed Factors That Modify the Effects of Time-Varying Factors: Applying the Case-Only Approach. Epidemiology, 14 (4), 467-472.

Baccini, M., Biggeri, A., Accetta, G., Kosatsky, T., Katsouyanni, K., Analitis, A., Anderson, H. R., Bisanti, L., D’Ippoliti, D., Danova J., ForsberG, B., Medina, S., Paldy, A., RabczenKo, D., Schindler, C. \& Michelozzi, P. (2008), Heat effects on mortality in 15 European cities. Epidemiology (Cambridge, Mass.), 19 (5),711-719. 
Baccini, M., Kosatsky, T., Analitis, A., Anderson, H. R., D’Ovidio, M., Menne, B., Michelozzi, P. \& Biggeri, A. (2011), Impact of heat on mortality in 15 European cities: attributable deaths under different weather scenarios. Journal of Epidemiology and Community Health 2011, 65, 64-70.

BASU, R. (2009), High ambient temperature and mortality: a review of epidemiologic studies from 2001 to 2008. Environmental Health, 8/2009, 40.

BASU, R. \& SAmET, J. M. (2002), Relation between Elevated Ambient Temperature and Mortality: A Review of the Epidemiologic Evidence. Epidemiologic Reviews , 24 (2), 190-202.

Bouchama, A., Dehbi, M., Mohamed, G., Matthies, F., Shoukri, M. \& Menne, B. (2007), Prognostic factors in heat wave related deaths: a meta-analysis. Archives of Internal Medicine, 167 (20), 2170-2176.

Dray, S., Legendre, P. \& Peres-Neto, P. R. (2006), Spatial modelling: a comprehensive framework for principal coordinate analysis of neighbour matrices (PCNM). Ecological Modelling, 196 (3-4), 483-493.

Fouillet, A., Rey, G., Wagner, V., LaAidi, K., Empereur-Bissonnet, P., LeTertre, A., Frayssinet, P., Bessemoulin, P., Laurent, F., De Crouy-Chanel, P., Jougla, E. \& HÉMON, D. (2008), Has the impact of heat waves on mortality changed in France since the European heat wave of summer 2003? A study of the 2006 heat wave. International Journal of Epidemiology, 37 (2), 309-317.

Gosling, S. N., Lowe, J. A., McGregor, G. R., Pelling, M. \& Malamud, B. D. (2008), Associations between elevated atmospheric temperature and human mortality: a critical review of the literature. Climatic Change, 92 (3-4), 299-341.

Hajat, S., Sheridan, S. C., Allen, M. J., Pascal, M., LaAidi, K., Yagouti, A., Bickis, U., Tobias, A., Bourque, D., Armstrong, B. G. \& Kosatsky, T. (2010), Heat-health warning systems: a comparison of the predictive capacity of different approaches to identifying dangerously hot days. American Journal of Public Health, 100 (6), 1137 1144.

Hansen, A., Bi, P., Nitschke, M., Ryan, P., Pisaniello, D. \& Tucker, G. (2008), The effect of heat waves on mental health in a temperate Australian city. Environmental Health Perspectives, 116 (10), 1369-1375.

IÑiguez, C., Ballester, F., Ferrandiz, J,. Pérez-Hoyos, S., SÁez, M. \& López, A. (2010), Relation between temperature and mortality in thirteen Spanish cities. International Journal of Environmental Research and Public Health, 7(8), 3196-3210.

Johnson, D. P., Wilson, J. S. \& LuBER, G. C. (2009), Socioeconomic indicators of heatrelated health risk supplemented with remotely sensed data. International Journal of Health Geographics, 8, 57.

Kestens, Y., Brand, A., Fournier, M., Goudreau, S., Kosatsky, T., Maloley, M. \& SMARGIASSI, A. (2011), Modelling the variation of land surface temperature as determinant of risk of heat-related health events. International Journal of Health Geographics, 10 (7).

Kinney, P. L., O’Neill, M. S., Bell, M. L. \& Schwartz, J. (2008), Approaches for estimating effects of climate change on heat-related deaths: challenges and opportuneties. Environmental Science \& Policy, 11, 87-96.

Kovats, R. S. \& Hajat, S, (2008), Heat Stress and Public Health: A Critical Review. Annual Review of Public Health, 29, 41-55.

LOGAN, M. (2010), Biostatistical design and analysis using R a practical guide. Chichester, UK; Hoboken, NJ, Wiley- Blackwell. 
Luber, G. \& McGeehin, M. (2008), Climate Change and Extreme Heat Events. American Journal of Preventive Medicine, 35 (5), 429-435.

Martin-Latry, K., Goumy, M., Latry, P., Gabinski, C., BéGaud, B., Faure, I. \& VerDOUX, H. (2007), Psychotropic drugs use and risk of heat-related hospitalisation. European Psychiatry, 22 (6), 335-338.

Matthies, F. \& MenNe, B. (2009), Prevention and management of health hazards related to heatwaves. International Journal of Circumpolar Health, 68, 8-22.

Medina-Ramón, M. \& Schwartz, J. (2008), Who is More Vulnerable to Die From Ozone Air Pollution? Epidemiology, 19 (5), 672-679.

MeEhl, G. A. \& TEBALDI, C. (2004), More Intense, More Frequent, and Longer Lasting Heat Waves in the 21st Century. Science, 305 (5686), 994-997.

Metzger, K. B., Ito, K. \& Matte, T. D. (2010), Summer heat and mortality in New York City: how hot is too hot? Environmental Health Perspectives, 118, 80-86.

NichOL, J. E., FunG, W. Y., LAM, K. S. \& WONG, M. S. (2009), Urban heat island diagnosis using ASTER satellite images and 'in situ' air temperature. Atmospheric Research, 94 (2), 276-284.

O’Neill, M. S., Carter, R., Kish, J. K., Gronlund, C. J., White-Newsome, J. L., ManAROLLA, X., ZANOBETTI, A. \& SCHWARTZ, J. D. (2009), Preventing heat-related morbidity and mortality: new approaches in a changing climate. Maturitas, 64 (2), 98-103.

Saez, M., SunYer, J., Tobias, A., BAllester, F. \& ANTÓ, J. M. (2000), Ischaemic heart disease mortality and weather temperature in Barcelona, Spain. The European Journal of Public Health, 10, 58-63.

SCHWARTZ, J. (2005a), Who is sensitive to extremes of temperature? A case-only analysis. Epidemiology (Cambridge, Mass.), 16, 67-72.

Schwartz, J. (2005b), How Sensitive Is the Association between Ozone and Daily Deaths to Control for Temperature? Am. J. Respir. Crit. Care Med., 171 (6), 627-631.

Smargiassi, A., Goldberg, M. S., Plante, C., Fournier, M., Baudouin, Y. \& KOSATSKY, T. (2009), Variation of daily warm season mortality as a function of microurban heat islands. Journal of Epidemiology and Community Health, 63 (8), 659-664. 